\title{
ATIVIDADE PULICIDA COMPARATIVO in vitro DO ÓLEO ESSENCIAL DE Cinnamomum cassia E DO CINAMALDEÍDO CONTRA Ctenocephalides felis
}

\author{
(Comparative pulicide activity in vitro of the essential oil Cinnamomum cassia and cinnamaldehyde against \\ Ctenocephalides felis felis)
} Cecília Lopes Conceição, Isabela Scalioni Gijsen, Emily Andressa Santos Lima, Jéssica Karoline Oliveira Chaves,
Diefrey Ribeiro Campos, Ingrid Lins Raquel Jesus, Yara Peluso Cid, Katherina Coumendouros

Universidade Federal Rural do Rio de Janeiro, Rio de Janeiro, Brasil.

*Correspondência: cecilialopes.vet@gmail.com

RESUMO: As pulgas da espécie Ctenocephalides felis (Siphonaptera: Pulicidae), são os insetos parasitos mais prevalentes em todo o mundo em cães e gatos. Estes parasitos são responsáveis por transmitir diversos agentes patogênicos de importância em saúde única. Além disso, podem causar irritação, espoliação sanguínea e provocar quadros de dermatite alérgica frente à antígenos presentes em sua saliva. Cinnamomum cassia, popularmente conhecida como canela, é uma árvore pequena pertencente a família Lauraceae. O óleo essencial (OE) extraído desta planta apresenta como constituinte majoritário o cinamaldeído que além de amplamente utilizado na culinária como flavorizante, possui atividades biológicas, incluindo atividade inseticida, repelente, antimicrobiana, antioxidantes e antiapoptótico. $\mathrm{O}$ objetivo deste trabalho foi comparar a atividade inseticida in vitro do óleo essencial de Ci. cassia e do cinamaldeído frente a pulgas adultas da subespécie $C$. felis felis. Para a realização do teste in vitro, foi preparada uma solução com contração $40000 \mu \mathrm{g} \cdot \mathrm{mL}^{-1}$ do óleo essencial de canela e do cinamaldeído. Posteriormente as soluções foram diluídas em acetona $20 \%$ de forma seriada (1:2) dez vezes. Foram utilizadas dez pulgas $C$. felis felis, não alimentadas, com 14 dias de idade, separadas em tubos de ensaio de vidro. Em seguida foi inserida uma fita de papel filtro Whatman $(80 \mathrm{~g}) \mathrm{com} 10 \mathrm{~cm}^{2}$ impregnada com $0,2 \mathrm{~mL}$ da solução obtendo as seguintes concentrações por área: de $800,400,200,100,50,25,12,5,6,25,3,12,1,56 \mu \mathrm{g} . \mathrm{cm}^{-2}$. Os desafios foram realizados em duplicata, além do controle constituído de uma fita de papel filtro impregnada com acetona a $20 \%$. O critério de avaliação utilizado foi a motilidade, portanto, pulgas que apresentassem qualquer tipo de movimento eram consideradas vivas. Foi registrado o número de pulgas vivas e mortas após 24 horas de exposição. $O$ percentual de mortalidade foi determinado utilizando a seguinte fórmula: mortalidade $(\%)$ = número de pulgas mortas X 100/número de pulgas incubadas. Com os resultados foi possível observar que após 24 horas de exposição do cinamaldeído a mortalidade foi de 5, 50 e 100\% nas concentrações de 6,25; 50,0 e $400 \mu \mathrm{g} . \mathrm{cm}^{-2}$ respectivamente. Já para OE de Ci. cassia, foi possível observar mortalidade de 5,55 e $100 \%$ nas concentrações de 6,25; 12,5; e $200 \mu \mathrm{g}_{\mathrm{cm}}{ }^{-2}$ respectivamente. Com base nos resultados obtidos neste trabalho é possível concluir que o OE de $\mathrm{Ci}$. cassia e seu constituinte majoritário, o cinamaldeído, apresentaram atividade inseticida in vitro frente ao estágio adulto de $C$. felis. No entanto, o OE de Ci. cassia apresentou mortalidade igual a $100 \% \mathrm{em}$ concentrações inferiores, propondo que outros constituintes no OE além do cinamaldeído podem ter potencializado a ação inseticida do cinamaldeído.

Palavra-chave: biocontrole, inseticida natural, canela, pulgas 